\title{
Perturbing Chromatin Structure to Understand Mechanisms of Gene Expression
}

\author{
Caroline R. Bartman ${ }^{1,2}$ and Gerd A. Blobel ${ }^{1,2}$ \\ ${ }^{1}$ Division of Hematology, Children's Hospital of Pennsylvania, Philadelphia, Pennsylvania 19104 \\ ${ }^{2}$ Perelman School of Medicine, University of Pennsylvania, Philadelphia, Pennsylvania 19104 \\ Correspondence: blobel@email.chop.edu
}

\begin{abstract}
The study of nuclear structure falls between the fields of cell biology and molecular biology and draws on techniques from both fields. In recent years, many exciting advances have been made in these areas, including single-molecule and superresolution imaging and the development of chromosome conformation capture (3C)-based technologies, which have brought the advent of genome-wide analysis of chromatin structure and contacts. However, many questions remain as to the function of nuclear structures, in particular their influence on transcription. Here we describe studies that have directly manipulated nuclear architecture at various levels and thus have clarified the causal influence of structure on transcription. We will also highlight open questions in the field, most notably regarding our understanding of the dynamics and variability in nuclear structure and its influence on gene expression.
\end{abstract}

Studies on diverse eukaryotic systems have revealed an influence of chromatin structural organization on gene expression (Bickmore 2013; Bickmore and van Steensel 2013; Nora et al. 2013; Deng and Blobel 2014; Sexton and Cavalli 2015). However, various levels of nuclear structure exert distinct degrees of influence on gene expression in different organisms, cell types, and gene loci. We will give examples of nuclear structures, with an emphasis on mammalian systems, and describe approaches that have been taken to manipulate them to elucidate their effects on gene expression. Finally, we will discuss the study of nuclear structural dynamics and will suggest much needed investigations into the functional relationship between nuclear structure and gene expression in populations and in single cells.

\section{NUCLEAR RADIAL POSITIONING}

Most broadly, association with the nuclear periphery has been associated with gene silencing, whereas transcribing genes are often found in the nuclear interior (Kosak et al. 2002; Bickmore 2013; Gibcus and Dekker 2013). Gene-rich chromosomes such as chromosome 19 in human cells tend to localize to the nuclear interior, whereas gene-poor chromosomes such as chromosome 18 tend to appear at the nuclear periphery (Cremer and Cremer 2010; Hübner and Spector 2010). In yeast, activated genes tend to localize to the interior or to nuclear pores, whereas silenced genes are targeted to the lamina (Brown et al. 2008; Ahmed et al. 2010). Lamina-associated domains (LADs) in mammalian cells tend to be correlated with the repressive chromatin marks $\mathrm{H} 3 \mathrm{~K} 27$ me3 and $\mathrm{H} 3 \mathrm{~K} 9 \mathrm{me} 3$, as well as gene-poor regions (Guelen et al. 2008; Bickmore and van Steensel 2013). In yeast, specific sequence "zip codes" can be sufficient to target genes to the periphery, suggesting a regulated process (Ahmed et al. 2010; Brickner et al. 2012). In mammalian cells, sequence-specific targeting to the lamina has also been described (Zullo et al. 2012). At the mammalian $\beta$ globin locus, a number of transcription factors, as well as the locus control region, a powerful distal enhancer, have been shown to be required both for transcriptional activation in erythroid cells as well as repositioning away from the nuclear periphery (Bulger and Groudine 2011; Krivega and Dean 2012). Intriguingly, nuclear localization may even play a role in viral infections: A recent study observed that genomic regions localizing to the nuclear pore in human cells are more likely to experience HIV integration during infection (Marini et al. 2015). All such observations suggest that localization to the nuclear periphery could play an evolutionarily conserved role in transcriptional silencing.

However, examples exist of cell types with alternative modes of heterochromatin organization. In retinal rod cells of nocturnal mammals, chromatin organization is reversed with heterochromatin localizing to the nuclear center and euchromatin at the periphery (Solovei et al. 2009). It is thought that this organization alters the refractive properties of nuclei to aid the transmission of photons under low light conditions. Another example in which nuclear compartmentalization follows distinct rules involves olfactory sensory neurons, which monoallelically express only one of more than a thousand olfactory receptor (OR) genes in any given cell (Clowney et al. 2012). The inactive OR genes cluster around heterochromatin toward the nuclear center. During cell differentiation, this clustering correlates with loss of lamin B receptor expression. Forced expression of the lamin $\mathrm{B}$ receptor leads decompaction of $\mathrm{OR}$ heterochromatic foci and coexpression of numerous OR genes, albeit at low levels, supporting a causal role of 
nuclear architecture in OR gene regulation. These observations suggest that the effects of nuclear localization might be determined by the local chromatin landscape rather than the nuclear position per se.

Studies that manipulate radial positioning have shown that nuclear localization can be functionally important, but not in all cases. First, it is important to note that although many studies saw significant changes in nuclear localization, such shifts tend not to be absolute: there is usually a high degree of heterogeneity in nuclear positioning of a locus among a cell population (Taddei et al. 2006; Toebin et al. 2012). Activation by tethering of the viral-derived transcriptional activators VP16 or VP64 to endogenous loci both induces transcription and moves loci farther from the nuclear periphery on average (Chuang et al. 2006; Therizols et al. 2014). However, it appears that nuclear relocalization was due to the acidic charge of VP64 rather than its transcriptional activity. Indeed, tethering a different acidic peptide lacking transcription activating function also mediated interior localization, uncoupling localization from transcription (Therizols et al. 2014). An acidic activation domain was also sufficient to destabilize peripheral LAD positioning without affecting transcription (Kind et al. 2013). Also suggesting a nondeterministic role for nuclear positioning in an "activating neighborhood" was a study in yeast, which showed that inducing the $H X K 1$ gene caused its translocation to a nuclear pore, but that tethering to a pore was not sufficient for transcription, although it did potentiate induction (Taddei et al. 2006).

Experiments that force genes to move to the nuclear lamina have had similarly varied effects. Artificial tethering of some genes to the nuclear lamina can mediate silencing of those genes, both in yeast and in mammalian cells (Andrulis et al. 1998; Finlan et al. 2008; Reddy et al. 2008). Moreover, in both mammalian cells and worms, the related repressive marks $\mathrm{H} 3 \mathrm{~K} 9 \mathrm{me} 3$ and $\mathrm{H} 3 \mathrm{~K} 9 \mathrm{me} 2$, respectively, were sufficient and necessary to target genes to the lamina (Toebin et al. 2012; Kind et al. 2013). However, for certain genes nuclear lamina tethering was not sufficient to repress transcription (Finlan et al. 2008; Kumaran and Spector 2008). A potential solution to the variable effects of lamina targeting was suggested by a very elegant experiment by van Steensel and colleagues: Lamina-associated chromatin was fluorescently tagged, and then these initial LADs were examined after cells had undergone division (Kind et al. 2013). First, LADs were not strictly inherited but only partially, showing that peripheral localization is nondeterministic. Moreover, only $30 \%$ of the total LAD pool, as measured in bulk cells, localized to the nuclear periphery in any given cell. This suggests that peripheral association is correlated with but is not absolutely necessary for silencing. Perhaps silenced domains tend to passively diffuse to the nuclear periphery, where the relative paucity of transcription factors and polymerase reinforces their silencing.

The example of the varying roles of peripheral localization in silencing illustrates both the importance of functional assays for interpreting the role of nuclear structure in gene expression and the power of imaging ap- proaches to clarify variability in structure between nuclei. The observation that the majority of structural patterns in the nucleus tend to be highly variable between cells suggests two models: (1) Nuclear structure may potentiate gene regulation while not being strictly required or (2) transient interactions with different genomic or nuclear elements could be sufficient to influence gene expression, as exemplified by the maintenance of nuclear localization patterns upon removal of the stimulus (Therizols et al. 2014). These are not necessarily mutually exclusive, but may both contribute to nuclear organization's influence on gene regulation.

\section{TOPOLOGICALLY ASSOCIATING DOMAINS}

The earliest image-driven approaches to nuclear structure encouraged studies of macroscale nuclear structures, such as the nuclear lamina, Polycomb bodies, and nucleolar-associated domains (Hübner and Spector 2010). In recent years, the application of formaldehyde cross-linking-based assays to measure proximity of genomic regions (e.g., 3C), and their application in a genome-wide manner (4C [circularized chromosome confirmation capture], 5C [carbon copy chromosome confirmation capture], and Hi-C [genome-wide chromosome confirmation capture]) (Dostie et al. 2006; Splinter et al. 2011; Naumova et al. 2013), have allowed examination of more fine-grained structures across the genome, including the recently discovered topologically associating domains (TADs). These domains range in size from 100 to $1000 \mathrm{~kb}$ and have been observed in both Drosophila and mammals (Sexton et al. 2012; Nora et al. 2013; Dixon et al. 2015), although they are not evident in yeast, bacteria, or Caenorhabditis elegans (Umbarger et al. 2011; Crane et al. 2015). These domains correlate with many previously observed functional properties of metazoan cells: TAD boundaries tend to colocalize with boundaries of replication domains, lamina-associated domains, CTCF (CCCTC-binding factor) binding sites, and transitions between regions characterized by histone marks including $\mathrm{H} 3 \mathrm{~K} 27 \mathrm{me} 3$, H3K4me3, and H3K9me3 (Dixon et al. 2012, 2015; Nora et al. 2012; Sexton et al. 2012; Kind et al. 2013; Phillips-Cremins et al. 2013; Pope et al. 2014). A majority of TAD borders in mammalian cells are bound by the insulator protein $\mathrm{CTCF}$, which can form homodimers and may help mediate the structure and folding of TADs (Dixon et al. 2012; Sexton et al. 2012; Phillips-Cremins et al. 2013). Moreover, the majority of enhancer-promoter contacts occurs within TADs rather than between them, and genes within the same TAD tend to be more correlated in their expression than average (Dixon et al. 2012; Nora et al. 2012). TADs are relatively conserved between cell types and even between species (Dixon et al. 2012, 2015; Nora et al. 2012). Human genetic variation that influences TAD structure can in some cases be correlated with altered gene expression, suggesting a causal role of TADs in shaping transcription (Dixon et al. 2015). Supporting such a conclusion, an unbiased assay of enhancer activity showed that enhancer activity 
is both distributed within a TAD and limited by TAD boundaries (Symmons et al. 2014). Given the above observations, TADs have been viewed as a fundamental structural unit of the metazoan genome.

The high degree of conservation between cell types and organisms suggests that TAD folding might be uniform between single cells of a population. Such a question is technically challenging to address. However, one pioneering study applied Hi-C to single cells and suggested that TAD contacts tend to be more consistent between single cells than larger cis contacts (Nagano et al. 2015). By placing DNA FISH probes either within or across TADs, intra-TAD contacts indeed were more common than interTAD contacts, though a high degree of variability was observed (Dixon et al. 2012; Nora et al. 2013). Computational modeling based on $5 \mathrm{C}$ data also suggests that TAD folding is dynamic (Giorgetti et al. 2014). Perhaps TADs overall may be more consistent than other nuclear contacts, but they are probably still quite labile over time.

These studies beg the question of how the structure of TADs is determined. In two studies, deletions of large boundary regions led to modest effects on cross-border contacts and gene expression (Nora et al. 2012; Andrey et al. 2013). Moreover, knockdown of CTCF altered but did not abrogate TAD structure (Zuin et al. 2014). Moreover, the sequence elements that determine TAD folding are not fully delineated. Targeted deletion of CTCF binding sites at TAD boundaries perturbed gene expression patterns supporting a role for CTCF in TAD delineation (Narendra et al. 2015). Surprisingly, in this case active chromatin dominantly spread into a previously silent domain, leading to aberrant gene activation. Moreover, in one recent report, deletions and inversions observed in human patients that cause limb malformations were due to the deletion of TAD boundaries, which allowed the inappropriate spreading of enhancer influence and inappropriate gene activation (Lupiáñez et al. 2015). Intriguingly, the groups of Heard and Dekker used a mathematical model of chromatin conformation to predict TAD-internal regions that were essential for structure (Giorgetti et al. 2014). Indeed, large deletions of three putative "master" structural elements within an X-chromosome TAD did appear to largely dissolve TAD structure, suggesting that boundary elements may collaborate with internal elements to structure TADs. Therefore, TAD boundaries could be one mechanism to reduce enhancer promiscuity. The field now awaits imaging of TAD dynamics in real time in single cells. This would allow an understanding of the kinetics of TAD formation after mitosis and the consistency of TADs over time in single cells. If TAD imaging could be paired with the MS2 RNA system, it might allow understanding of the correlation between TAD dynamics and transcription (Darzacq et al. 2007).

\section{ENHANCER-PROMOTER LOOPS}

For a number of years, contacts between genes and enhancers have been theorized to control gene transcription (Krivega and Dean 2012; Levine et al. 2014). It is thought that enhancers preferentially contact their target promoter to transfer, or increase the local concentration of, RNA Pol II and transcription factors (Bulger and Groudine 2011; Calo and Wysocka 2013). In many cases, it appears that enhancers activate promoters with some degree of selectivity (van Arensbergen et al. 2014); in fact, a recent study shows that in embryonic stem (ES) cells, only $66 \%$ of active promoters genome-wide contact the nearest enhancer, whereas others appear to be controlled by more distal elements (Schoenfelder et al. 2015). Therefore, the specific contacts between promoters and enhancers may be key structural elements in controlling transcription. Many studies have shown that deletion of proteins important for transcription of a locus abrogate looping and also gene expression (Drissen 2004; Vakoc et al. 2005; Song et al. 2007). However, affecting both parameters at once fails to answer the question of causation: Is looping required for enhancer activation, or is it simply a consequence of activation? Moreover, in typical loss of function experiments involving transcription factors, secondary effects on global gene expression and chromosome folding cannot be excluded. In several plasmid-based systems, which allowed specific rather than global manipulation of DNA topology, forced enhancer-promoter juxtaposition was sufficient for transcription (Mueller-Storm et al. 1989; Petrascheck et al. 2005; Nolis et al. 2009). However, gene regulation in plasmids can be markedly different from native gene loci. Recent studies address these issues by showing that targeted tethering of $\mathrm{Ldb} 1$, a factor involved in enhancer-promoter looping, was sufficient for gene activation at the native, unaltered murine and human $\beta$ globin loci (Deng et al. 2012, 2014). This also indicates that at some loci chromosome looping might be the last and rate-determining step for transcription (Vernimmen et al. 2007). However, extensive enhancer-promoter contact structures can also exist before gene activation-for example, at the TH2 cytokine gene locus (Spilianakis and Flavell 2004). More recently, using the Hi$\mathrm{C}$ method to examine chromosome conformation before and after TNF- $\alpha$ stimulation, it was found that many induced genes had preexisting enhancer-promoter interactions (Jin et al. 2014). It is possible that these different types of interaction dynamics reflect divergent and perhaps separable modes of enhancer function, such as "opening" chromatin or recruitment of basal transcription factors, versus stimulating transcription elongation (Bulger and Groudine 2011; Schwarzer and Spitz 2014). It is also possible that signal-responsive immediate-early promoter-enhancer pairs are present in poised loops, to enable rapid inductive transcriptional responses.

Studies using guided manipulation of enhancer-promoter contacts might be useful for select therapeutic applications. For example, forced enhancer contacts with the fetal type $\beta$-like globin gene ( $\gamma$-globin) strongly activated its expression in primary adult human erythroblasts and commensurately lowered expression of the adult type $\beta$-globin gene (Deng et al. 2014). This approach might be useful in diseases in which elevated fetal globin gene expression is beneficial such as sickle cell 
disease and some forms of $\beta$-thalassemia. In addition, dynamically altering contacts between enhancers and promoters or other regulatory regions might be exploited to study mechanisms of enhancer function.

Many questions remain to be answered to clarify the dynamics, sufficiency, and mechanism of enhancer-promoter looping. First, as mentioned above, enhancer-promoter contacts have been suggested to perform a variety of functions including RNA Pol II transfer and promoting elongation, and it is not clear which may be most important globally, or whether different enhancers might perform different functions (Bulger and Groudine 2011). Another level of complexity is raised by the observation from $3 \mathrm{C}$ based studies that many promoters may contact multiple enhancers in the same cell type, either simultaneously or alternately (Sanyal et al. 2012; Kieffer-Kwon et al. 2013; Jin et al. 2014; Schoenfelder et al. 2015). Finally, there is little understanding of the dynamics of enhancer-promoter interactions. For example, is an enhancer required to continuously contact its target gene to enable transcription or is it simply required to set up the locus during development, leaving the gene to fire independently subsequent to activation? Alternatively, do looped contacts persist following gene inactivation and perhaps contribute to transcriptional memory? Because genes often contact multiple enhancers (Schoenfelder et al. 2015), do they all come together in a rosette around the promoter or does each contact the gene with specialized dynamics?

\section{DYNAMICS OF NUCLEAR STRUCTURES}

A deeper understanding of the dynamics of nuclear structure will be required to clarify its effects on transcription. One fundamental question of structural dynamics is whether nuclear structure can be inherited across mitosis. During mitosis, chromosomes are condensed, territories are reorganized, most transcription factors are evicted from chromatin, and structures including TADs disappear (Naumova et al. 2013). Perhaps as a result of this global disruption, many structures are not recapitulated exactly after mitosis. LADs are largely redistributed (Kind et al. 2013) along with other structures such as nucleolar-associated domains (Hübner and Spector 2010). Certain parameters may be carried over between mitosis and might aid structural reconstitution to some extent: Certain transcription factors and histone modifications remain associated with mitotic chromatin to mediate gene reactivation via a "bookmarking" mechanism (Kadauke and Blobel 2013; Wang and Higgins 2013). At certain sites architectural proteins such as CTCF may remain bound and may even stably maintain certain chromatin loops (Burke et al. 2005). It will be intriguing to measure mitotic binding of architectural proteins like CTCF in a genome-wide manner, to examine whether TAD boundaries themselves are bookmarked.

It is also important to understand the lability of nuclear structures and contacts during the interphase to understand the impact of structure on transcription. Fixed-cell imaging of large populations of cells can uncover the spectrum of possible chromatin conformations and sug- gest an inherent variability over time. For example, DNA fluorescence in situ hybridization (FISH) of TADs, LADs, and radial positioning of genes suggests that they can vary highly between cells under uniform conditions (Nora et al. 2012; Kind et al. 2013; Therizols et al. 2014). Fixed-cell imaging can also be powerfully used in genetic screens for factors involved in nuclear architecture: Two elegant examples include a screen for determinants of Polycomb bodies in murine cells and of LADs in C. elegans (Toebin et al. 2012; Gonzalez et al. 2014). In the future, an exciting possibility may be to use higher-throughput RNA FISH methods to allow more comprehensive connections to be made between nuclear architecture and transcription (Chen et al. 2015; Lee et al. 2015). However, ultimately to understand dynamics and stability of genomic organization, live-imaging approaches must also be used.

Such live-imaging studies tend to be technically demanding and low-throughput, but they provide invaluable insight. Few studies explicitly examining nuclear structure have been undertaken, but the techniques are under development. One elegant study performed by Misteli and colleagues induced simultaneous breakages in two chromosomes marked by tagged arrays and then visualized the joining events. This led to the observation that broken ends tend not to separate, or to increase their speed of movement, and that nuclear confinement dictates that neighboring breaks are much more likely to be rejoined (Roukos et al. 2013). Such techniques could be applied to intact loci in different developmental or genetic contexts to understand the function of nuclear structure. Along these lines, one study visualized a locus involved in rearrangement of the immunoglobulin locus in B cells and quantified the highly efficient process of finding its recombination target (Lucas et al. 2014). Excitingly, the CRISPR/Cas9 technology should now allow endogenous loci to be imaged without genetically altering them (Chen et al. 2013). Future studies could label two or more loci to address promoter-enhancer dynamics, or intra-TAD contact dynamics, by imaging in real time at native loci.

\section{CONCLUSION}

Studies of nuclear structure have revealed both cases in which structures appear strongly influential for gene expression and counterexamples of genes and chromatin marks that appear unaffected by structural alterations. Though intriguing trends have emerged, this suggests that there is further complexity to be understood before we will be able to draw predictive inferences about gene expression from knowledge of structure. Predictive power will be gained by further mechanistic studies, as well as by live-imaging approaches to help understand the dynamics and heterogeneity of different facets of nuclear structure.

\section{REFERENCES}

Ahmed S, Brickner DG, Light WH, Cajigas I, McDonough M, Froyshteter AB, Volpe T, Brickner JH. 2010. DNA zip codes 
control an ancient mechanism for gene targeting to the nuclear periphery. Nat Cell Biol 12: 111-118.

Andrey G, Montavon T, Mascrez B, Gonzalez F, Noordermeer D, Leleu M, Trono D, Spitz F, Duboule D. 2013. A switch between topological domains underlies HoxD genes collinearity in mouse limbs. Science 340: 1234167.

Andrulis ED, Neiman AM, Zappulla DC, Sternglanz R. 1998. Perinuclear localization of chromatin facilitates transcriptional silencing. Nature 394: 592-595.

Bickmore WA. 2013. The spatial organization of the human genome. Annu Rev Genomics Hum Genet 14: 67-84.

Bickmore WA, van Steensel B. 2013. Genome architecture: Domain organization of interphase chromosomes. Cell 152: $1270-1284$.

Brickner DG, Ahmed S, Meldi L, Thompson A, Light W, Young M, Hickman TL, Chu F, Fabre E, Brickner JH. 2012. Transcription factor binding to a DNA zip code controls interchromosomal clustering at the nuclear periphery. Dev Cell 22: 1234-1246.

Brown CR, Kennedy CJ, Delmar VA, Forbes DJ, Silver PA. 2008. Global histone acetylation induces functional genomic reorganization at mammalian nuclear pore complexes. Genes Dev 22: 627-639.

Bulger M, Groudine M. 2011. Functional and mechanistic diversity of distal transcription enhancers. Cell 144: 327-339.

Burke LJ, Zhang R, Bartkuhn M, Tiwari VK, Tavoosidana G, Kurukuti S, Weth C, Leers J, Galjart N, Ohlsson R, et al. 2005. CTCF binding and higher order chromatin structure of the $\mathrm{H} 19$ locus are maintained in mitotic chromatin. EMBO J 24: $3291-3300$

Calo E, Wysocka J. 2013. Modification of enhancer chromatin: What, how, and why? Mol Cell 49: 825-837.

Chen B, Gilbert LA, Cimini BA, Schnitzbauer J, Zhang W, Li G-W, Park J, Blackburn EH, Weissman JS, Qi LS, et al. 2013. Dynamic imaging of genomic loci in living human cells by an optimized CRISPR/Cas system. Cell 155: 14791491.

Chen KH, Boettiger AN, Moffitt JR, Wang S, Zhuang X. 2015. RNA imaging. Spatially resolved, highly multiplexed RNA profiling in single cells. Science 348: aaa6090.

Chuang CH, Carpenter AE, Fuchsova B, Johnson T, de Lanerolle P, Belmont AS. 2006. Long-range directional movement of an interphase chromosome site. Curr Biol 16: 825-831.

Clowney EJ, LeGros MA, Mosley CP, Clowney FG, Markenskoff-Papadimitriou EC, Myllys M, Barnea G, Larabell CA, Lomvardas S. 2012. Nuclear aggregation of olfactory receptor genes governs their monogenic expression. Cell 151: 724737.

Crane E, Bian Q, McCord RP, Lajoie BR, Wheeler BS, Ralston EJ, Uzawa S, Dekker J, Meyer BJ. 2015. Condensin-driven remodelling of $\mathrm{X}$ chromosome topology during dosage compensation. Nature 523: 240-244.

Cremer T, Cremer M. 2010. Chromosome territories. Cold Spring Harb Perspect Biol 2: a003889.

Darzacq X, Shav-Tal Y, de Turris V, Brody Y, Shenoy SM, Phair RD, Singer RH. 2007. In vivo dynamics of RNA polymerase II transcription. Nat Struct Mol Biol 14: 796-806.

Deng W, Blobel GA. 2014. Manipulating nuclear architecture. Curr Opin Genet Dev 25: 1-7.

Deng W, Lee J, Wang H, Miller J, Reik A, Gregory PD, Dean A, Blobel GA. 2012. Controlling long-range genomic interactions at a native locus by targeted tethering of a looping factor. Cell 149: 1233-1244.

Deng W, Rupon JW, Krivega I, Breda L, Motta I, Jahn KS, Reik A, Gregory PD, Rivella S, Dean A, et al. 2014. Reactivation of developmentally silenced globin genes by forced chromatin looping. Cell 158: 849-860.

Dixon JR, Selvaraj S, Yue F, Kim A, Li Y, Shen Y, Hu M, Liu JS, Ren B. 2012. Topological domains in mammalian genomes identified by analysis of chromatin interactions. Nature 485 : $376-380$.

Dixon JR, Jung I, Selvaraj S, Shen Y, Antosiewicz-Bourget JE, Lee AY, Ye Z, Kim A, Rajagopal N, Xie W, et al. 2015.
Chromatin architecture reorganization during stem cell differentiation. Nature 518: 331-336.

Dostie J, Richmond TA, Arnaout RA, Selzer RR, Lee WL, Honan TA, Rubio ED, Krumm A, Lamb J, Nusbaum C, et al. 2006. Chromosome conformation capture carbon copy (5C): A massively parallel solution for mapping interactions between genomic elements. Genome Res 16: 1299-1309.

Drissen R. 2004. The active spatial organization of the $\beta$-globin locus requires the transcription factor EKLF. Genes Dev 18: 2485-2490.

Finlan LE, Sproul D, Thomson I, Boyle S, Kerr E, Perry P, Ylstra B, Chubb JR, Bickmore WA. 2008. Recruitment to the nuclear periphery can alter expression of genes in human cells. PLoS Genet 4: e1000039.

Gibcus JH, Dekker J. 2013. The hierarchy of the 3D genome. Mol Cell 49: 773-782.

Giorgetti L, Galupa R, Nora EP, Piolot T, Lam F, Dekker J, Tiana G, Heard E. 2014. Predictive polymer modeling reveals coupled fluctuations in chromosome conformation and transcription. Cell 157: 950-963.

Gonzalez I, Mateos-Langerak J, Thomas A, Cheutin T, Cavalli G. 2014. Identification of regulators of the three-dimensional polycomb organization by a microscopy-based genome-wide RNAi screen. Mol Cell 54: 485-499.

Guelen L, Pagie L, Brasset E, Meuleman W, Faza MB, Talhout W, Eussen BH, de Klein A, Wessels L, de Laat W, et al. 2008. Domain organization of human chromosomes revealed by mapping of nuclear lamina interactions. Nature 453: $948-$ 951.

Hübner MR, Spector DL. 2010. Chromatin dynamics. Annu Rev Biophys 39: 471-489.

Jin F, Li Y, Dixon JR, Selvaraj S, Ye Z, Lee AY, Yen C-A, Schmitt AD, Espinoza CA, Ren B. 2014. A high-resolution map of the three-dimensional chromatin interactome in human cells. Nature 503: 290-294.

Kadauke S, Blobel GA. 2013. Mitotic bookmarking by transcription factors. Epigenetics Chromatin 6: 6.

Kieffer-Kwon KR, Tang Z, Mathe E, Qian J, Sung MH, Li G, Resch W, Baek S, Pruett N, Grontved L, et al. 2013. Interactome maps of mouse gene regulatory domains reveal basic principles of transcriptional regulation. Cell 155: 1507-1520.

Kind J, Pagie L, Ortabozkoyun H, Boyle S, de Vries SS, Janssen $\mathrm{H}$, Amendola M, Nolen LD, Bickmore WA, van Steensel B. 2013. Single-cell dynamics of genome-nuclear lamina interactions. Cell 153: 178-192.

Kosak ST, Skok JA, Medina KL, Riblet R, Le Beau MM, Fisher AG, Singh H. 2002. Subnuclear compartmentalization of immunoglobulin loci during lymphocyte development. Science 296: $158-162$.

Krivega I, Dean A. 2012. Enhancer and promoter interactionsLong distance calls. Curr Opin Genet Dev 22: 79-85.

Kumaran RI, Spector DL. 2008. A genetic locus targeted to the nuclear periphery in living cells maintains its transcriptional competence. J Cell Biol 180: 51-65.

Lee JH, Daugharthy ER, Scheiman J, Kalhor R, Ferrante TC, Terry R, Turczyk BM, Yang JL, Lee HS, Aach J, et al. 2015. Fluorescent in situ sequencing (FISSEQ) of RNA for gene expression profiling in intact cells and tissues. Nat Protoc 10: $442-458$

Levine M, Cattoglio C, Tjian R. 2014. Looping back to leap forward: Transcription enters a new era. Cell 157: 13-25.

Lucas JS, Zhang Y, Dudko OK, Murre C. 2014. 3D trajectories adopted by coding and regulatory DNA elements: First-passage times for genomic interactions. Cell 158: 339-352.

Lupiáñez DG, Kraft K, Heinrich V, Krawitz P, Brancati F, Klopocki E, Horn D, Kayserili H, Opitz JM, Laxova R, et al. 2015. Disruptions of topological chromatin domains cause pathogenic rewiring of gene-enhancer interactions. Cell 161: $1012-1025$.

Marini B, Kertesz-Farkas A, Ali H, Lucic B, Lisek K, Manganaro L, Pongor S, Luzzati R, Recchia A, Mavilio F, et al. 2015. Nuclear architecture dictates HIV-1 integration site selection. Nature 521: 227-231. 
Mueller-Storm HP, Sogo JM, Schaffner W. 1989. An enhancer stimulates transcription in trans when attached to the promoter via a protein bridge. Cell 58: 767-777.

Nagano T, Lubling Y, Stevens TJ, Schoenfelder S, Yaffe E, Dean W, Laue ED, Tanay A, Fraser P. 2015. Single-cell Hi$\mathrm{C}$ reveals cell-to-cell variability in chromosome structure. Nature 502: 59-64.

Narendra V, Rocha PP, An D, Raviram R, Skok JA, Mazzoni EO, Reinberg D. 2015. Transcription. CTCF establishes discrete functional chromatin domains at the Hox clusters during differentiation. Science 347: 1017-1021.

Naumova N, Imakaev M, Fudenberg G, Zhan Y, Lajoie BR, Mirny LA, Dekker J. 2013. Organization of the mitotic chromosome. Science 342: 948-953.

Nolis IK, McKay DJ, Mantouvalou E, Lomvardas S, Merika M, Thanos D. 2009. Transcription factors mediate long-range enhancer-promoter interactions. Proc Natl Acad Sci 106: 20222-20227.

Nora EP, Lajoie BR, Schulz EG, Giorgetti L, Okamoto I, Servant N, Piolot T, van Berkum NL, Meisig J, Sedat J, et al. 2012. Spatial partitioning of the regulatory landscape of the X-inactivation centre. Nature 485: $381-385$.

Nora EP, Dekker J, Heard E. 2013. Segmental folding of chromosomes: A basis for structural and regulatory chromosomal neighborhoods? Bioessays 35: 818-828.

Petrascheck M, Escher D, Mahmoudi T, Verrijzer CP, Schaffner W, Barberis A. 2005. DNA looping induced by a transcriptional enhancer in vivo. Nucleic Acids Res 33: 3743-3750.

Phillips-Cremins JE, Sauria ME, Sanyal A, Gerasimova TI, Lajoie BR, Bell JS, Ong C-T, Hookway TA, Guo C, Sun Y, et al. 2013. Architectural protein subclasses shape 3D organization of genomes during lineage commitment. Cell 153: $1281-1295$.

Pope BD, Ryba T, Dileep V, Yue F, Wu W, Denas O, Vera DL, Wang Y, Hansen RS, Canfield TK, et al. 2014. Topologically associating domains are stable units of replication-timing regulation. Nature 515: 402-405.

Reddy KL, Zullo JM, Bertolino E, Singh H. 2008. Transcriptional repression mediated by repositioning of genes to the nuclear lamina. Nature 452: 243-247.

Roukos V, Voss TC, Schmidt CK, Lee S, Wangsa D, Misteli T. 2013. Spatial dynamics of chromosome translocations in living cells. Science 341: 660-664.

Sanyal A, Lajoie BR, Jain G, Dekker J. 2012. The long-range interaction landscape of gene promoters. Nature 489: 109113.

Schoenfelder S, Furlan-Magaril M, Mifsud B, Tavares-Cadete F, Sugar R, Javierre B-M, Nagano T, Katsman Y, Sakthidevi M, Wingett SW, et al. 2015. The pluripotent regulatory circuitry connecting promoters to their long-range interacting elements. Genome Res 25: 582-597.

Schwarzer W, Spitz F. 2014. The architecture of gene expression: Integrating dispersed cis-regulatory modules into coherent regulatory domains. Curr Opin Genet Dev 27: 74-82.

Sexton T, Cavalli G. 2015. The role of chromosome domains in shaping the functional genome. Cell 160: 1049-1059.

Sexton T, Yaffe E, Kenigsberg E, Bantignies F, Leblanc B, Hoichman M, Parrinello H, Tanay A, Cavalli G. 2012. Three-dimensional folding and functional organization principles of the Drosophila genome. Cell 148: 458-472.
Solovei I, Kreysing M, Lanctot C, Kosem S, Peichl L, Cremer T, Guck J, Joffe B. 2009. Nuclear architecture of rod photoreceptor cells adapts to vision in mammalian evolution. Cell 137: 356-368.

Song SH, Hou C, Dean A. 2007. A positive role for NLI/Ldb1 in long-range $\beta$-globin locus control region function. Mol Cell 28: $810-822$.

Spilianakis CG, Flavell RA. 2004. Long-range intrachromosomal interactions in the $\mathrm{T}$ helper type 2 cytokine locus. Nat Immunol 5: 1017-1027.

Splinter E, de Wit E, Nora EP, Klous P, van de Werken HJ, Zhu Y, Kaaij LJ, van IJcken W, Gribnau J, Heard E, et al. 2011. The inactive $\mathrm{X}$ chromosome adopts a unique three-dimensional conformation that is dependent on Xist RNA. Genes Dev 25: $1371-1383$.

Symmons O, Uslu VV, Tsujimura T, Ruf S, Nassari S, Schwarzer W, Ettwiller L, Spitz F. 2014. Functional and topological characteristics of mammalian regulatory domains. Genome Res 24: 390-400.

Taddei A, Van Houwe G, Hediger F, Kalck V, Cubizolles F, Schober H, Gasser SM. 2006. Nuclear pore association confers optimal expression levels for an inducible yeast gene. Nature 441: 774-778.

Therizols P, Illingworth RS, Courilleau C, Boyle S, Wood AJ, Bickmore WA. 2014. Chromatin decondensation is sufficient to alter nuclear organization in embryonic stem cells. Science 346: $1238-1242$.

Toebin BD, González-Aguilera C, Sack R, Gaidatzis D, Kalck V, Meister P, Askjaer P, Gasser SM. 2012. Step-wise methylation of histone $\mathrm{H} 3 \mathrm{~K} 9$ positions heterochromatin at the nuclear periphery. Cell 150: 934-947.

Umbarger MA, Toro E, Wright MA, Porreca GJ, Baù D, Hong SH, Fero MJ, Zhu LJ, Marti-Renom MA, McAdams HH, et al. 2011. The three-dimensional architecture of a bacterial genome and its alteration by genetic perturbation. Mol Cell 44: $252-264$.

Vakoc CR, Letting DL, Gheldof N, Sawado T, Bender MA, Groudine M, Weiss MJ, Dekker J, Blobel GA. 2005. Proximity among distant regulatory elements at the $\beta$-globin locus requires GATA-1 and FOG-1. Mol Cell 17: 453-462.

van Arensbergen J, van Steensel B, Bussemaker HJ. 2014. In search of the determinants of enhancer-promoter interaction specificity. Trends Cell Biol 24: 695-702.

Vernimmen D, De Gobbi M, Sloane-Stanley JA, Wood WG, Higgs DR. 2007. Long-range chromosomal interactions regulate the timing of the transition between poised and active gene expression. EMBO J 26: 2041-2051.

Wang F, Higgins JMG. 2013. Histone modifications and mitosis: Countermarks, landmarks, and bookmarks. Trends Cell Biol 23: $175-184$

Zuin J, Dixon JR, van der Reijden MIJA, Ye Z, Kolovos P, Brouwer RWW, van de Corput MPC, van de Werken HJG, Knoch TA, van IJcken WFJ, et al. 2014. Cohesin and CTCF differentially affect chromatin architecture and gene expression in human cells. Proc Natl Acad Sci 111: 996-1001.

Zullo JM, Demarco IA, Piqué-Regi R, Gaffney DJ, Epstein CB, Spooner CJ, Luperchio TR, Bernstein BE, Pritchard JK, Reddy KL, et al. 2012. DNA sequence-dependent compartmentalization and silencing of chromatin at the nuclear lamina. Cell 149: 1474-1487. 


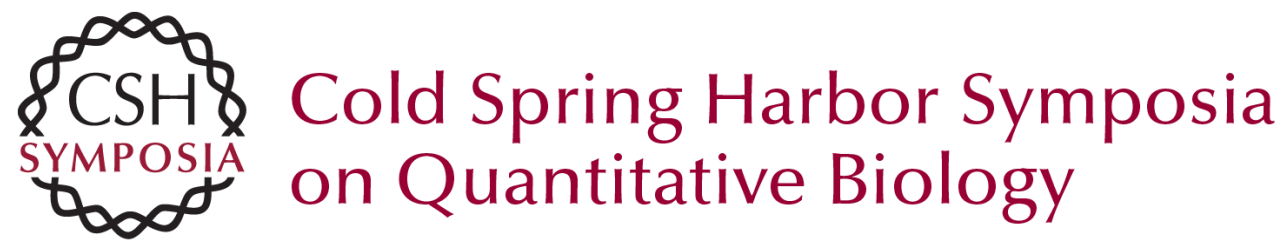

\section{Perturbing Chromatin Structure to Understand Mechanisms of Gene Expression}

Caroline R. Bartman and Gerd A. Blobel

Cold Spring Harb Symp Quant Biol 2015 80: 207-212 originally published online September 14, 2015

Access the most recent version at doi:10.1101/sqb.2015.80.027359

References This article cites 74 articles, 19 of which can be accessed free at: http://symposium.cshlp.org/content/80/207.full.html\#ref-list-1

\section{License}

Email Alerting Receive free email alerts when new articles cite this article - sign up in Service the box at the top right corner of the article or click here. 